\title{
Using an Inflation-Augmented Price-Earnings Ratio to Guide Tactical Asset Allocation
}

\author{
AD Saville ${ }^{1}$ \\ Gordon Institute of Business Science, University of Pretoria
}

\begin{abstract}
Asset allocation plays a central role in determining investment outcomes, and available evidence shows that portfolio results can be enhanced through tactical asset allocation if managers use the simple price-earnings ratio as a predictor of equity returns. Recently, some international evidence has emerged which shows that, by augmenting the price-earnings metric with information about consumer price inflation, further enhancements can be achieved in tactical asset allocation. This study reviews these arguments as they apply to South Africa, and finds that an inflation-augmented price-earnings ratio is more successful in forecasting equity returns than is the simple price-earnings ratio. Moreover, the metric is found to be significant in explaining relative asset class returns. On a risk-adjusted basis, however, the tool fails to improve the portfolio results when compared to a buy-and-hold strategy.
\end{abstract}

Abstract

JEL G11, 12, 14

\section{1 \\ Introduction}

Asset allocation plays a central role in determining the results of active portfolio management, with tactical asset allocation offering potentially substantial improvements in investment results for skilled market timers. However, the evidence reflected in the international literature shows that active portfolio managers generally lack skill in tactical asset allocation. Nevertheless, the substantial theoretical attraction of tactical asset management remains, so the search for tools that aid asset allocation is ongoing. On this front, there is some evidence to suggest that the price-earnings ratio is a powerful predictor of equity returns. Yet the evidence is not without qualification. For instance, active managers who avoided equities because of high price-earnings ratios during the second half of the 1990s would have missed out on the exceptional returns generated over that period. There is thus a motivation for better asset allocation signals.

On this score, an augmented price-earnings ratio, which is calculated by adding a measure of consumer price inflation to the price-earnings ratio, appears to be a strong candidate for replacing the simple price-earnings ratio as an asset allocation tool for tactical asset allocators. The reason for this is that, although it can be shown that price inflation should have a neutral impact on equity returns (Ritter \& Warr, 2002), this is not the case in practice, as various biases and sources of error are introduced into valuations during periods of high price inflation. Consequently, the inflation-augmented priceearnings ratio, or IAPE metric, captures information about equity valuations that a simple price-earnings ratio fails to recognise.

Given these arguments, this paper examines the forecasting performance of the IAPE metric relative to the price-earnings ratio in the case of South Africa. Section 2 considers the importance of asset allocation to the portfolio management function. Sections 3 and 4 review the early evidence and theoretical justification for using a price-earnings ratio augmented with inflation data as a platform for enhancing tactical asset allocation. Section 5 describes the 25-year data set employed in this study, while Section 
6 shows that the IAPE measure produces a better forecasting performance than the simple price-earnings ratio in predicting returns from equities. From this result, Section 7 goes on to establish that the IAPE metric is significant in explaining relative asset class returns. Using the results of an experiment performed on a sub-sample of the data, Section 8 shows that the IAPE metric could have been used to guide tactical asset allocation in improving portfolio returns over the sample period. However, on a risk-adjusted basis, the tool fails to improve the portfolio results produced by tactical asset allocation in comparison with a buy-and-hold strategy. Section 9 focuses on concluding comments.

\section{2}

\section{The importance of asset allocation ${ }^{1}$}

Portfolio performance is determined by three main factors: asset allocation, stock selection and the trading activity that follows from the first two aspects of portfolio management (Bodie, Kane \& Marcus, 2005:861-893). Although there is a tendency for practitioners to emphasise the roles played by stock picking and trading activity in determining portfolio performance, the evidence from academic research demonstrates that, of these three factors, asset allocation has the greatest influence over the results of portfolio management.

By way of example, Brinson, Hood and Beebower (1986), Brinson, Singer and Beebower (1991) and Ibbotson and Kaplan (2000) have all found that between 80 and 94 percent of the variation in quarterly performance of professionally-managed portfolios is explained by the mix of equities, bonds and cash. This finding, however, is not new. For instance, more than half a century ago Graham and Dodd (1951:12) noted:
“... there is no longer any clear-cut evidence of an underlying and persistent upward trend in common stocks [equities] taken as a whole. Their chartered history carries both a promise of excellent gains when purchases are made in depressed markets and a warning of a possible permanent loss

if the investor buys when bullish sentiment is at its greatest."

From these arguments and evidence it follows that successful portfolio management begins with appropriate asset allocation. In this vein, in the case of actively-managed portfolios, which are designed to outperform a passive benchmark, there are two elements of successful asset allocation, namely strategic asset allocation and tactical asset allocation (Darst, 2003:3-39). Strategic asset allocation refers to the task of building portfolios so that the weights in which the different asset classes are held are consistent with pre-specified portfolio characteristics (such as a targeted rate of return or compliance with risk parameters). Of course, the range of assets that might be considered in a decision about strategic asset allocation is potentially wide, and includes domestic and offshore equities, bonds, cash, commodity funds and hedge funds. In turn, each asset class has specific long-run risk and return attributes and, as pointed out above, when blended in different combinations, the asset class mix is designed to result in a portfolio that caters for individual mandate requirements such as the portfolio time horizon; income necessities; the call for purchasing-power protection or nominal capital value protection; and the investor's ability to tolerate portfolio price volatility.

Once the strategic asset allocation decision has been made, the focus of active portfolio management turns to tactical asset allocation. As noted by Dumont de Chassart and Firer (2001:19) tactical asset allocation - or market timing - refers to changes in the proportions invested in each asset class in an actively managed portfolio. ${ }^{2}$ These changes in asset class exposure are effected to improve portfolio performance relative to a benchmark by enhancing portfolio returns, reducing portfolio risk or producing some combination of these two improvements (Darst, 2003:26-31). These tactical adjustments to asset allocation are a consequence of the portfolio manager's view on the likely market impacts - and so portfolio results - of factors such as changes in the economic setting or alteration in the business cycle stage; economic, investment and political risks; the extent to 
which asset markets display signs of distress, exhaustion or exuberance; changes in asset class quality; structural adjustments in the economy and/or capital markets; and the relative valuations evident on the different asset classes (Ferson \& Schadt, 1996).

In its most extreme form, pure tactical asset allocation involves a complete switch from one asset class to another, depending on the forecasts made by the portfolio manager (Chance \& Hemler, 2001:379). However, it is most commonly the case that tactical asset allocation involves "tilting" exposure to the different asset classes. In other words, tactical asset allocation typically deals with questions of degree rather than all-or-nothing outcomes. In either event, though, the success of tactical asset allocation is dependent on how accurately the portfolio manager can predict the future returns and other investment characteristics of the different asset classes (Dumont de Chassart \& Firer, 2001:19). Certainly, if every market upturn or downturn could be predicted, then portfolio results produced by such active management would be substantially better than those produced by a passive buy-and-hold strategy. Indeed, Statman (2000) argues that strategic asset allocation is equivalent to a movement along the efficient frontier, whereas tactical asset allocation involves movement of the efficient frontier.

To illustrate the potential impact of successful tactical asset allocation on portfolio performance, Shilling (1992) examined the effect on annual investment returns of being able to stay out of the market (represented by equities listed on the New York Stock Exchange) during bad months. He concluded that an investor who missed the 50 weakest months between 1946 and 1991 would have seen annual returns hike from 11.2 percent to 19.0 percent. In similar fashion, in the case of South African markets, Firer, Ward and Teeuwisse (1987) showed that a passive investment in the Johannesburg Stock Exchange's (JSE's) All Share Index (ALSI) over the period 1967 to 1986 would have grown 45 -fold. However, investors with perfect knowledge who switched their portfolio between equities and Treasury bills would have seen their investment grow 665 -fold over the same period. Alternatively, had the portfolio been in the wrong asset class all the time, quarterly switching would have reduced the investment value by a factor of eight. Firer, Sandler and Ward (1992) use monthly data from 1967 to 1989 of the JSE ALSI and the S\&P 500 to determine whether market timing is a worthwhile strategy. Their findings point to enhanced returns with successful market timing. Interestingly, they find a seven percent standard deviation of returns for the buy-and-hold strategy compared to the four percent for the managed portfolio, suggesting that successful tactical asset allocation can reduce risk (Firer, Sandler \& Ward, 1992:321).

In short, the theoretical attractions of tactical asset allocation are material, and, if tactical asset allocation were costless, it would make sense to attempt to time the market, given the huge potential returns offered by successful tactical asset allocation. However, tactical asset allocation is not a costless activity, and there are at least four costs associated with trying to time markets. First, in the process of switching from one asset class to another, portfolios incur transactions costs. The size of these costs depends on the size of the portfolio and the extent to which timing is practised, but the costs erode potential gains. Second, tactical asset allocation activities increase potential tax liabilities either by causing portfolio gains to be classified as income where trading activity is high, or, where gains are of a capital nature, capital gains tax is brought forward in the portfolio lifecycle. Third, portfolio returns may also be compromised by liquidity constraints, buy-sell stock spreads and markets gapping away from investors as they try to move between asset classes. Fourth, in practising tactical asset allocation, it is possible that investors miss the best return periods in specific asset classes as a result of imperfect forecasts.

3

\section{Tactical asset allocation}

"In forming our expectations, it would be foolish to attach great weight to matters that are very uncertain. It is reasonable, therefore, to be guided to a considerable 
degree by the facts about which we feel somewhat confident ..."

(John Maynard Keynes, 1936:148)

Various rules have been put forward by researchers to guide tactical asset allocation. Amongst the more simple rules to apply in the case of equities are those that pertain to the price-earnings ratio, which is a measure of the number of Rands that investors are willing to pay per Rand of earnings. According to conventional wisdom, the higher the price-earnings ratio of the market (or the more investors are willing to pay per unit of earnings), the more overvalued the market is likely to be. Lower price-earnings ratios are therefore argued to be indicative of a good time for investors to buy equities, while high price-earnings ratios are indicative of equities being expensive (Graham, 1959; Basu, 1977). This idea has been empirically tested by Bleiberg (1989) and Good (1991). ${ }^{3}$ In their studies, the authors found that the market's price-earnings ratio is inversely correlated with subsequent market returns. In other words, low price-earnings ratios signalled high market returns and high price-earnings ratios were generally followed by low market returns.

However, experience in the case of equity markets in the United States (US) in the mid1990s motivates for improvements on the simple price-earnings ratio rule. To be more specific, those who believed that high price-earnings ratios are a signal that equities are expensive would have missed out on the go-go years of the late 1960s; the bull market of the 1980s and the robust market returns of the second half of the 1990s that were generated by US equities. These traded on price-earnings ratios that were substantially in excess of their long-run average or, in other words, were high. With the advantage of hindsight, some researchers have attempted to explain this apparent contradiction by claiming that high price-earnings ratios are justified by low price inflation (Tanner, 1999:59). This explanation has yielded an alternative metric, the inflation-augmented price-earnings ratio, or IAPE, which is produced by adding the annualised consumer price inflation rate to the market's price-earnings ratio. The IAPE replaces the simple price-earnings ratio as the key point of measurement in predicting market returns.
Early evidence of the relationship between equity returns and price inflation was provided by Fisher (1930) and further extended by both Jaffe and Mandelker (1976) and Fama and Schwert (1977), who found that equity returns are negatively related to price inflation. However, others have gone further to identify specific rules for guiding tactical asset allocation. Tanner (1999), for example, suggests that, if the sum of the price-earnings ratio and consumer price inflation rate is less that 20, equities are inexpensive. By contrast, if the metric is greater than 20 , equity investors should be wary of a declining market. This result has produced the so-called Rule of 20. In a study covering the sixty-year period 1935-1995, Tanner (1999:59) shows that a US $\$ 1,000$ passive investment in equities would have grown to over US\$134,000. However, an investor with knowledge of the Rule of 20 would have accumulated over US $\$ 244,000$ by tactically allocating assets to Treasury bills when the IAPE measure was greater than 20.

Of course, Tanner's (1999) finding meets with the immediate objection that there is no theoretical basis for the number 20 to operate as the factor separating expensive equity markets from cheap equity markets. This objection is not refuted. Looking beyond it, however, at least two material questions of practical importance in tactical asset allocation remain. First, is the IAPE metric effective in guiding tactical asset allocation decisions in other markets? Second, if so, is the result an improvement over the priceearnings ratio which, various sources have noted, offers value as a market timing indicator? This paper attempts to answer these questions by comparing the forecasting ability of the IAPE metric and the simple price-earnings ratio in the case of South Africa.

\section{4 \\ The price-earnings ratio, consumer price inflation rate and the IAPE metric}

From empirical observation it follows that price inflation and equity returns are inversely related. For instance, Ritter and Warr (2002:35) note: 
"In the 1970s, the real level of the Dow [Jones Industrial Average] fell, while inflation averaged $8.7 \%$ per year. Only in the $1980 \mathrm{~s}$ with the decline in inflation did the Dow recover and make significant real gains. These patterns are consistent with the hypothesis that the high inflation of the mid and late 1970s and early 1980s led to systematic undervaluation of equities ... With the low inflation of the 1990s, this undervaluation ended."

These observed relationships between the priceearnings ratio, consumer price inflation rate and equity performance require some detailed comment, which is set out below.

As Ritter and Warr (2002) point out, the correct value of a firm's equity can be computed by capitalising nominal cash flows to equity holders at a risk-adjusted nominal rate, or real cash flows at a risk-adjusted real rate. Assuming a constant discount rate, price inflation and real growth rate so that a simple single-stage growth model can be used, it follows that the two methods are equivalent:

Equation 1

$P_{0}=\frac{D_{0}(1+g)}{(r-g)}$

\section{Equation 2}

$P_{0}=\frac{D_{0}(1+g)(1+p)}{r(1+p)-g(1+p)}=\frac{D_{0}(1+g)}{R-G}$

where $P_{0}$ is the present value of the perpetuity of cash flows, beginning with $D_{1} ; D_{t}$ is the expected dividends per share for period $t ; r$ is the market's required real rate of return; $g$ is the real growth rate of dividends; $R$ is the market's required nominal rate of return; and $G$ is the nominal growth rate of dividends.

Further, assuming the identity:

$D_{t}=\operatorname{HEPS}_{t} \cdot P O$

where $P O$ is the firm's dividend payout ratio of earnings at time $t$ and $H E P S_{0}$ is the most recent measure of accounting headline earnings per share, then Equations 1 and 2 can be rearranged as:

\section{Equation 3}

$P_{0}=\frac{P O \cdot H E P S_{0}(1+g)}{(r-g)}$

\section{Equation 4}

$P_{0}=\frac{P O \cdot \text { HEPS }_{0}(1+g)(1+p)}{R-G}$

Using the popular press form of the priceearnings ratio:

\section{Equation 5}

\section{$\frac{P_{0}}{H E P S_{0}}$}

It follows that the impact of price inflation on the fair value price-earnings ratio is identified as neutral:

\section{Equations $6 a$ and $6 b$}

$\frac{P_{0}}{H E P S_{0}}=\frac{P O \cdot(1+g)}{(r-g)}=\frac{P O \cdot(1+g)}{R-G}$

Anticipated inflation is incorporated into the equation through the nominal required rate of return. In periods of high inflation, investors require a high rate of return and, as $\mathrm{R}$ rises, the price-earnings ratio falls. However, the nominal growth rate of earnings (G), ceteris paribus, will also be high in periods of high inflation, consequently sterilising the effect of inflation on the real value of the stock. The effect of inflation on the real value of the stock will thus be neutral. Consequently, the impacts of price inflation on the different valuation components sterilise one another. This means that, in contravention of the observations of Tanner (1999) and others, augmenting price-earnings information with inflation data should carry no information in tactical asset allocation decision-making.

However, Ritter and Warr (2002) demonstrate that price inflation impacts on valuation ratios in a number of ways. The sources of error, which are varied, include investors using a nominal discount rate while failing to incorporate a higher nominal growth rate (Ritter \& Warr, 2002:31); investors employing high inflation as a proxy for slower economic growth (Fama, 1981); the biasing of real earnings forecasts downward in inflationary periods (Sharpe, 2002); and historically-based depreciation expensing resulting in higher taxation and 
lower real cash flows (Feldstein, 1980). In the presence of these sources of error, it follows that price inflation does not have a neutral impact on equity valuations. Instead, during periods of high inflation, equities become overvalued, while during periods of low inflation they become undervalued. If these arguments hold in other environments, it follows that tactical asset allocation decisions could benefit from augmenting price-earnings information with inflation data. Below, this argument is tested with regard to the South African case.

\section{5}

\section{Data description}

This study uses a lengthy price-earnings ratio time series from Datastream, spanning the period January 1980 to December 2006, and the consumer price inflation index produced by Statistics South Africa. In line with Tanner (1999), the IAPE metric is calculated as the sum of the consumer price inflation rate and the historical price-earnings ratio. The historical price-earnings ratio is calculated as the end of month value of the All Share Index divided by the reported earnings of the most recent twelve months for the index. In the case of price inflation, by convention, South Africa's consumer price inflation data are available with a lag of just under two months. ${ }^{4}$ The consumer price inflation figure used is the year-on-year increase in the Consumer Price Index (CPI), as reported by Statistics South Africa, lagged by two months. For example, the IAPE metric for January uses November's CPI announcement to calculate the metric. ${ }^{5}$ To ensure that all information is available at time $t$, when the tactical asset allocation decision is taken, the observed price-earnings ratio for the last trading day of the previous month is used to calculate the current month's IAPE metric. For example, the IAPE measure for January each year is calculated by using the price-earnings ratio drawn from the last trading day of the previous December plus the November CPI.

Table 1 provides descriptive statistics of the priceearnings ratio, price inflation and IAPE data. One of the most important statistics is the correlation over the time series between the price-earnings ratio, which is traditionally used to indicate market valuation levels, and the IAPE metric.

With a correlation of 0.54 , the two measures show some degree of independence; this suggests that the IAPE metric can be used as an independent alternative to the priceearnings ratio in guiding tactical asset allocation decisions. The monthly price-earnings ratio over the period 1980-2006 averaged 12.72, with a median of 12.60 . The price-earnings ratio ranged between a maximum of 23.80 , reached in September 1994, and a minimum of 3.40, reached in July 1982. The price-earnings ratio exhibits a standard deviation of 3.59.

Table 1

Summary statistics 1980-2006

\begin{tabular}{|c|c|c|}
\hline & Price-earnings ratio & IAPE metric \\
\hline Mean & 12.72 & 23.17 \\
Median & 12.60 & 22.10 \\
Standard Deviation & 4.31 & 5.44 \\
Maximum & 23.80 & 37.00 \\
Minimum & 3.40 & 12.30 \\
Quintile 1 & 15.50 & 26.39 \\
Quintile 2 & 13.23 & 23.40 \\
Quintile 3 & 11.36 & 20.95 \\
Quintile 4 & 9.00 & 18.97 \\
Quintile 5 & & 0.54 \\
Correlation & & \\
\hline
\end{tabular}

Source: Adapted from Datastream and McGregor-BFA 
In contrast, the monthly IAPE metric has an average of 23.17 , with a median of 22.10. In itself, this is an interesting outcome, indicating that "common" application of the IAPE metric under the guise of the Rule of 20 would suggest that, on average, equities were an expensive asset class over the sample period. This observation reinforces the earlier point that the value of 20 (under the Rule of 20) is essentially nonsensical. Rather, the greater value resides in the shared information on price inflation and the market's rating. In other words, different markets may revert to different IAPE metrics. As evidence of this, the IAPE metric for the US over the period 1935-1995 averaged 17.72. Perversely, though, the IAPE metric for the US over the period 1980-2006 averaged 23.14 - a figure almost identical to that for South Africa. ${ }^{6}$ That said, the highest figure for the South African market of 37.00 was reached in August 1987, shortly before the sharp equity market correction of October 1987. At that time the equity market was trading on a price earnings ratio of 19.70 times and the price inflation figure measured 17.30 percent. The minimum score on the IAPE metric of 12.30 was recorded in January 2004, with the market trading on a priceearnings multiple of 11.90 times and price inflation measuring 0.40 percent. At 5.44, the standard deviation on the IAPE metric is higher in absolute terms than that on the price-earnings ratio (4.31), but lower relative to the mean. Figure 1 shows the price-earnings data and IAPE metric time-series for the sample period 1980-2006.

Following the method employed by Bleiberg (1989) and Tanner (1999), to test the predictive power of the price-earnings ratios and IAPE metric, the data are sorted into quintiles based on their levels. The total returns (that is capital gains plus dividend and other income receipts) generated by equities over the next month, three months, six months and one year, are then calculated for each sample period based on an investment in the JSE's ALSI. The forecasting tests in the next section compare the subsequent returns for each quintile of price-earnings ratios and IAPE metrics.

Figure 1

Price-Earnings Ratio and IAPE Metric (1980-2006)

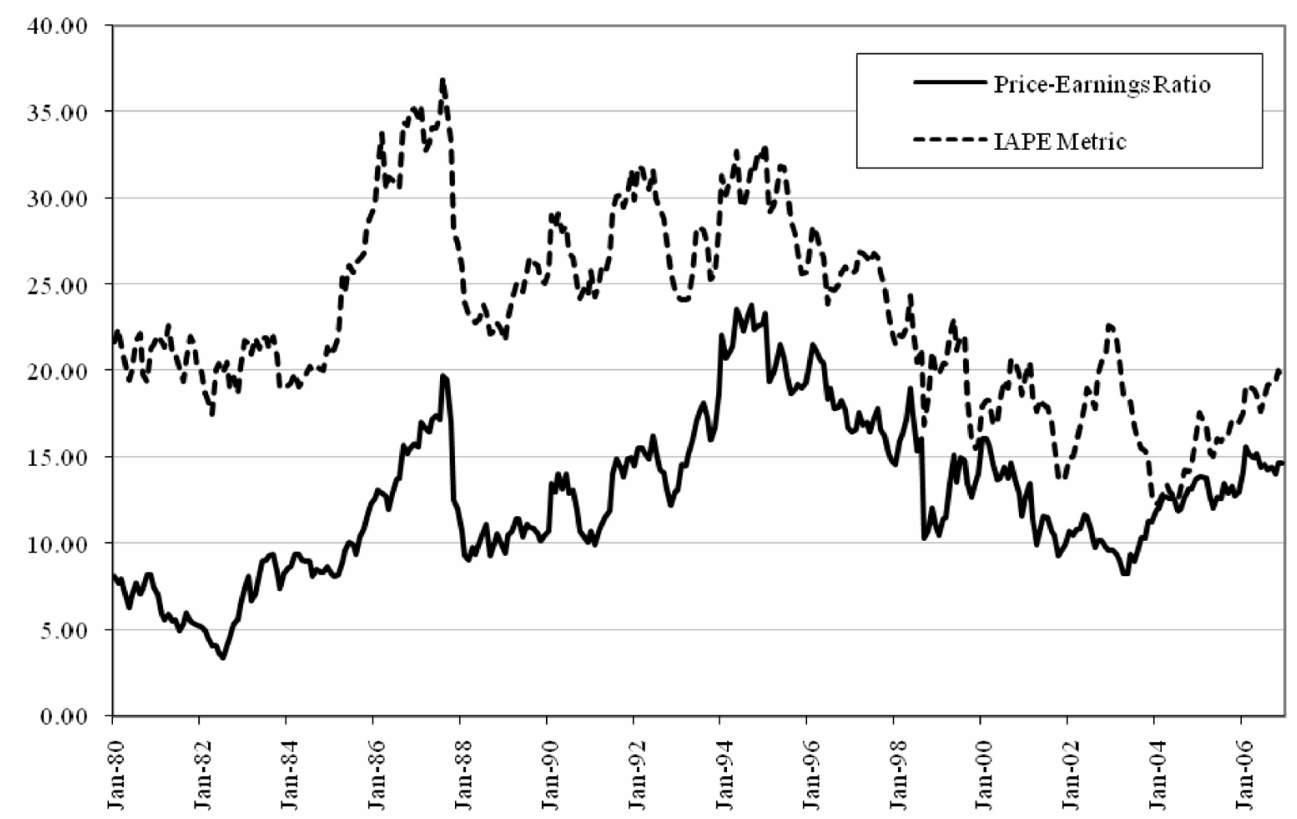

Source: Adapted from Datastream and McGregor-BFA 


\section{6}

\section{Forecasting equity returns}

Table 2 shows the average total return offered by equities in the months following each measurement; Table 3 ranks the returns. ${ }^{7}$ Based on theory and empirical observations, it is expected that the price-earnings measure and IAPE metric are inversely related to subsequent market movements. Specifically, the theory set out above postulates that the lower the priceearnings ratio and IAPE metric, the more equity prices should rise in subsequent periods.

Based on the simple quintile analysis, the results set out in Tables 2 and 3 show that the predictive relationship between the priceearnings ratio and market movements was relatively strong over the sample period. In all of the periods analysed, and specifically in the case of the price-earnings ratio, the highest price-earnings ratios were followed by the lowest returns. Further, the second highest price earnings quintile produced the second lowest returns over all periods except for 12 months when the third lowest returns were produced. Additional support for the theory is provided by the result that the fourth quintile produced the second highest returns in all periods except the one month return period, in which case the highest returns were generated. However, contrary to expectations, the median quintile produced the highest subsequent returns in all periods except over one month. Moreover, the lowest price-earnings quintile, which is forecast to produce the highest returns, produced median returns in all periods except over one year, in which instance it resulted in the second lowest return rate. From this, it is argued that the price-earnings ratio is a useful - but not unambiguous - guide to subsequent returns, particularly in the case of high priceearnings ratios.

Table 2

ALSI returns (\%) by quintile 1980-2006

\begin{tabular}{|c|c|c|c|c|}
\hline & \multicolumn{4}{|c|}{ Average ALSI return over subsequent period (\%) } \\
\hline Price-earnings quintile & One month & Three months & Six months & One year \\
\hline 1 (Highest) & 0.60 & 0.50 & 1.00 & 3.91 \\
\hline 2 & 0.78 & 3.48 & 6.98 & 11.27 \\
\hline 3 & 1.44 & 5.25 & 11.36 & 27.06 \\
\hline 4 & 1.57 & 4.23 & 8.87 & 15.37 \\
\hline 5 (Lowest) & 1.12 & 3.91 & 7.02 & 10.17 \\
\hline & & Average ALSI return over subsequent period (\%) & One year \\
\hline IAPE metric quintile & One month & Three months & Six months & 7.89 \\
\hline 1 (Highest) & 0.58 & 1.72 & 3.59 & 13.49 \\
\hline 2 & 1.14 & 3.50 & 8.15 & 11.25 \\
\hline 3 & 0.00 & 1.89 & 4.84 & 13.69 \\
\hline 4 & 2.35 & 4.63 & 7.01 & 21.83 \\
\hline
\end{tabular}

As far as the IAPE metric is concerned, the results show strong predictive power in the lowest and second lowest quintiles. Specifically, as shown in Tables 2 and 3, over all periods, the lowest quintile for the IAPE metric is associated with the highest rate of return. Further, the second lowest quintile is associated with the second highest returns over all periods except 
for six months, when there was the third highest rate of return in the sample period. Similarly, in the case of the highest quintile, the IAPE metric successfully predicts the poorest rate of return over all periods, except one month, where the ranking is fourth.
However, as with the price-earnings ratio, not all quintiles are equally reliable as predictors of returns. For instance, the second highest quintile is associated with the second highest rate of return over six months, and the median quintile produces the second lowest and lowest rates of return; these results are contrary to expectation.

Table 3

Ordinal rankings of ALSI returns by quintile 1980-2006

\begin{tabular}{|c|c|c|c|c|}
\hline \multirow[b]{2}{*}{ Price-earnings quintile } & \multicolumn{4}{|c|}{ Average ALSI return over subsequent period (\%) } \\
\hline & One month & Three months & Six months & One year \\
\hline 1 (Highest) & 5 & 5 & 5 & 5 \\
\hline 2 & 4 & 4 & 4 & 3 \\
\hline 3 & 2 & 1 & 1 & 1 \\
\hline 4 & 1 & 2 & 2 & 2 \\
\hline \multirow[t]{2}{*}{5 (Lowest) } & 3 & 3 & 3 & 4 \\
\hline & \multicolumn{4}{|c|}{ Average ALSI return over subsequent period (\%) } \\
\hline IAPE metric quintile & One month & Three months & Six months & One year \\
\hline 1 (Highest) & 4 & 5 & 5 & 5 \\
\hline 2 & 3 & 3 & 2 & 3 \\
\hline 3 & 5 & 4 & 4 & 4 \\
\hline 4 & 2 & 2 & 3 & 2 \\
\hline 5 (Lowest) & 1 & 1 & 1 & 1 \\
\hline
\end{tabular}

In summary, as in the case of price-earnings ratios, the results of the quintile analysis show that the IAPE metric is not perfectly consistent with the ordinal return outcomes expected. However, this does not mean the two methods are redundant. The price earnings ratio provides better forecasts on the highest quintile for all periods, and can thus be used to predict returns for the highest quintile. The IAPE metric performs better in predicting stock returns for the lowest quintile in all periods and can be used to predict returns for the lowest quintile. This suggests that the two models can be used as complements in forecasting stock returns for the highest quintiles (using the price-earnings ratio) and the lowest quintiles (using the IAPE metric) in which they all perform better in comparison with the middle quintiles.
Caveats aside, the quintile analysis shows that the price-earnings ratio and the IAPE metric are reasonably useful guides in tactical asset allocation, especially where the measures are in extreme states. However, as an indication of predictive power, the analysis is not sufficient to establish the relative predictive power of the two tools. To establish this, two linear models are estimated:

\section{Equation 7}

Total Return $_{i}=\alpha+\beta$ PER $_{t}$ and

\section{Equation 8}

Total Return $_{i}=\alpha+\beta$ IAPE $_{t}$

where the subscript $i$ denotes subsequent one-, three-, six- and twelve-month return periods, 
$\mathrm{PER}_{\mathrm{t}}$ denotes the price-earnings ratio and IAPE $_{\mathrm{t}}$ denotes the IAPE metric in each period $(t)$. Regression estimates based on the monthly sample data $(n=324)$ for the period 1980-2006 are presented in Table 4.

The results of the estimation procedure reveal that, in the case of the price-earnings model, the coefficients take the correct sign over all periods, although the co-efficient of the one-month model is not statistically significant at the five percent level. For the three-month model, the coefficient estimate is significant at the five percent level, and at the one percent level in the case of the six-month and twelve-month models. Significantly, the coefficient behaves monotonically with the length of the forecast period, which reinforces the suggestion that the price-earnings ratio is useful when indicating the direction and magnitude of returns over all of the forecast periods, although over the very near-term the explanatory power is not significant. Despite this outcome, the low adjusted- $\mathrm{R}^{2}$ statistics reveal that the price-earnings ratio explains no more than 1.83 percent of the market's variation over the forecast periods.

Table 4

Regression estimation 1980-2006

\begin{tabular}{|c|c|c|c|}
\hline $\begin{array}{l}\text { Total return model } \\
\text { (Total return })\end{array}$ & Intercept $(\alpha)$ & Coefficient on PER $_{t}(\beta)$ & Adjusted- $\mathbf{R}^{2}$ \\
\hline \multirow[t]{2}{*}{ One-month } & 12.79 & -0.06 & $0.31 \%$ \\
\hline & $(0.000)$ & $(0.067)$ & \\
\hline \multirow[t]{2}{*}{ Three-month } & 7.33 & -0.30 & $1.12 \%$ \\
\hline & $(0.000)$ & $(0.017)$ & \\
\hline \multirow[t]{2}{*}{ Six-month } & 13.99 & -0.54 & $1.83 \%$ \\
\hline & $(0.000)$ & $(0.005)$ & \\
\hline \multirow[t]{2}{*}{ One-Year } & 22.91 & -0.74 & $1.74 \%$ \\
\hline & $(0.000)$ & $(0.005)$ & \\
\hline $\begin{array}{l}\text { Total return model } \\
\left(\text { Total return }{ }_{\mathrm{i}}\right)\end{array}$ & Intercept $(\alpha)$ & $\begin{array}{l}\text { Coefficient on } \\
\text { IAPE }_{t}(\beta)\end{array}$ & Adjusted- $\mathbf{R}^{2}$ \\
\hline \multirow[t]{2}{*}{ One-month } & 3.43 & -0.10 & $0.76 \%$ \\
\hline & $(0.003)$ & $(0.023)$ & \\
\hline \multirow[t]{2}{*}{ Three-month } & 9.66 & -0.27 & $1.45 \%$ \\
\hline & $(0.000)$ & $(0.007)$ & \\
\hline \multirow[t]{2}{*}{ Six-month } & 16.53 & -0.41 & $1.58 \%$ \\
\hline & $(0.000)$ & $(0.008)$ & \\
\hline \multirow[t]{2}{*}{ One-year } & 31.50 & -0.77 & $3.20 \%$ \\
\hline & $(0.000)$ & $(0.001)$ & \\
\hline
\end{tabular}

In the case of the inflation-augmented model, the estimates for IAPE are significant at the five percent level in the case of one month and at the one percent level in the case of the three-, six- and twelve-month models, and take the correct sign in all periods. In the case of the one-month model, it is estimated that a one-unit increase in the IAPE metric is followed by a 10 basis 
point decline in returns. Over three months, six months and one year the decline in returns is 27 basis points, 41 basis points and 77 basis points respectively. The adjusted- $\mathrm{R}^{2}$ statistics suggest that the inflation-augmented models are generally more powerful in explaining market variations than the price-earnings models. Despite the higher explanatory power of the inflation-augmented models, the IAPE metric explains just 3.20 percent of the variation in market returns. However, this is expected in a market that is at least reasonably efficient.

\section{7 \\ Extending the case to two asset classes}

While the results presented above show that the price-earnings ratio and IAPE metric have some power in forecasting equity returns, the analysis ignores opportunity costs. Specifically, the purpose of tactical asset allocation is to move capital to risk-carrying assets (such as equities) when prospects for the asset class are positive, but to shift this exposure to "risk-free" assets, such as government bonds, when prospects are poor. The return offered by the risk-free asset class may thus be thought of as the opportunity cost of being in the equities market. The market return less the riskless asset class return is therefore the gain (or loss) that investors receive from investing in equities (relative return).

To test the forecasting strength of the priceearnings ratio and IAPE metric in relation to asset allocation, relative equity returns are calculated by taking the difference between the return on the ALSI less the return on shortdated government bonds over subsequent one-, three-, six- and twelve-month periods. As in the case of the total return analysis, it is expected that the price-earnings ratio and IAPE metric will be inversely related to subsequent relative equity returns. ${ }^{9}$

Table 5

Relative ALSI returns (\%) by quintile 1980-2006

\begin{tabular}{|c|c|c|c|c|}
\hline & \multicolumn{5}{|c|}{ Average ALSI return over subsequent period (\%) } \\
\hline Price-earnings quintile & One month & Three months & Six months & One year \\
\hline 1 (Highest) & -0.77 & -2.41 & -5.06 & -8.47 \\
\hline 2 & -0.33 & -0.59 & -1.23 & -5.47 \\
\hline 3 & -0.47 & 0.89 & 2.37 & 7.55 \\
\hline 4 & 0.51 & 0.38 & 1.92 & -0.27 \\
\hline 5 (Lowest) & 0.96 & 1.91 & 2.52 & 0.95 \\
\hline & \multicolumn{2}{|c|}{ Average ALSI return over subsequent period (\%) } \\
\hline IAPE metric quintile & One month & Three months & Six months & One year \\
\hline 1 (Highest) & -0.48 & -2.42 & -4.94 & -9.77 \\
\hline 2 & -0.14 & -0.80 & -0.21 & -1.96 \\
\hline 3 & -1.04 & 0.06 & 0.29 & -0.40 \\
\hline 4 & 0.42 & 1.36 & 1.04 & -0.32 \\
\hline 5 (Lowest) & 1.64 & 1.96 & 4.25 & 6.93 \\
\hline
\end{tabular}

Tables 5 and 6 provide summaries of the relative returns and rank in relative returns per quintile. From these results, it is evident that the two metrics are more effective in predicting relative asset class returns than they are in predicting total equity returns 
(Tables 2 and 3). However, the improvement in the accuracy of predictions based on the price-earnings ratio is marginal, with the method correctly ranking 11 of 16 possible outcomes (as opposed to 10 out of 16 in the case of total equity returns). In contrast, the improvement in the accuracy of predictions based on the IAPE metric is more significant. Specifically, the IAPE metric correctly ranks 13 of 16 results (as opposed to 10 out of 16 in the case of total equity returns), with the three incorrect predictions all occurring over the one-month forecast period. Thus, the IAPE quintiles are perfectly ordinal over all forecast periods except for the one-month period, whereas the price-earnings ratio fails to rank any period with a perfectly ordinal result.
The relative predictive strength of the IAPE metric over the price-earnings ratio is confirmed by estimating linear models that explain relative equity returns:

\section{Equation 9}

Relative Return $_{i}=\alpha+\beta$ PER $_{t}$ and

\section{Equation 10}

Relative Return $_{i}=\alpha+\beta$ IAPE $_{t}$

where the subscript $i$ denotes subsequent one-, three-, six- and twelve-month return periods, $\mathrm{PER}_{t}$ denotes the price-earnings ratio and IAPE $_{t}$ denotes the IAPE metric in each period $(t)$. Regression estimates based on the monthly sample data $(n=324)$ for the period 1980-2006 are presented in Table 7.

Table 6

Relative ordinal rankings of ALSI returns by quintile 1980-2006

\begin{tabular}{|c|c|c|c|c|}
\hline & \multicolumn{5}{|c|}{ Average ALSI return over subsequent period (\%) } \\
\hline Price-earnings quintile & One month & Three months & Six months & One year \\
\hline 1 (Highest) & 5 & 5 & 5 & 5 \\
\hline 2 & 3 & 4 & 4 & 4 \\
\hline 3 & 4 & 2 & 2 & 1 \\
\hline 4 & 2 & 3 & 3 & 3 \\
\hline 5 (Lowest) & 1 & 1 & 1 & 2 \\
\hline & \multicolumn{4}{|c|}{ Average ALSI return over subsequent period (\%) } \\
\hline IAPE metric quintile & One month & Three months & Six months & One year \\
\hline 1 (Highest) & 4 & 5 & 5 & 5 \\
\hline 2 & 3 & 4 & 4 & 4 \\
\hline 3 & 5 & 3 & 3 & 3 \\
\hline 4 & 2 & 2 & 2 & 1 \\
\hline 5 (Lowest) & 1 & 1 & 1 & 2 \\
\hline
\end{tabular}

The results of the estimation procedure show that, in the case of the price-earnings model, the coefficient takes the correct sign over all periods and that the subsequent decline in returns behaves monotonically. The results accord closely with those generated in the case of the total return model. Further, as in the case of the total return model, the price-earnings ratio is found to be useful in indicating the direction and magnitude of returns, with the strength of the result increasing as the forecast period increases. However, the low adjusted- $\mathrm{R}^{2}$ statistic indicates that the priceearnings ratio explains less than three percent of the variation in relative returns. 
In the case of the inflation-augmented model, the estimate of the coefficient on IAPE over one month takes the correct sign but it is not statistically significant at the five percent level. Further, the low adjusted- $\mathrm{R}^{2}$ statistic suggests that the IAPE metric is not significant in explaining returns over one month. However, over the three-, six- and twelve-month forecast periods the coefficients on IAPE take the correct sign and all are significant at the one percent level. The adjusted- $\mathrm{R}^{2}$ statistics suggest that the power of the inflation-augmented models increases with the forecast period, with the metric explaining as much as 7.22 percent of the variation in relative returns over subsequent one-year periods.

\section{Table 7}

Regression estimation 1980-2006 ${ }^{10}$

\begin{tabular}{|c|c|c|c|}
\hline $\begin{array}{l}\text { Relative return model } \\
\quad\left(\text { Relative return }{ }_{\mathrm{i}}\right)\end{array}$ & Intercept $(\alpha)$ & Coefficient on PER $(\beta)$ & Adjusted-R ${ }^{2}$ \\
\hline \multirow[t]{2}{*}{ One-Month } & 2.00 & -0.16 & $1.43 \%$ \\
\hline & $(0.026)$ & $(0.017)$ & \\
\hline \multirow[t]{2}{*}{ Three-Month } & 3.70 & -0.29 & $1.10 \%$ \\
\hline & $(0.041)$ & $(0.033)$ & \\
\hline \multirow[t]{2}{*}{ Six-Month } & 6.92 & -0.54 & $2.03 \%$ \\
\hline & $(0.008)$ & $(0.006)$ & \\
\hline \multirow[t]{2}{*}{ One-Year } & 8.87 & -0.79 & $2.94 \%$ \\
\hline & $(0.007)$ & $(0.001)$ & \\
\hline $\begin{array}{l}\text { Relative return model } \\
\left.\text { (Relative return }{ }_{i}\right)\end{array}$ & Intercept $(\alpha)$ & $\begin{array}{l}\text { Coefficient on } \\
\text { IAPE }_{t}(\beta)\end{array}$ & Adjusted-R ${ }^{2}$ \\
\hline \multirow[t]{2}{*}{ One-Month } & 3.43 & -0.10 & $0.76 \%$ \\
\hline & $(0.008)$ & $(0.063)$ & \\
\hline \multirow[t]{2}{*}{ Three-Month } & 7.90 & -0.34 & $2.81 \%$ \\
\hline & $(0.002)$ & $(0.002)$ & \\
\hline \multirow[t]{2}{*}{ Six-Month } & 13.24 & -0.57 & $3.81 \%$ \\
\hline & $(0.000)$ & $(0.000)$ & \\
\hline \multirow[t]{2}{*}{ One-Year } & 21.23 & -0.96 & $7.22 \%$ \\
\hline & $(0.000)$ & $(0.000)$ & \\
\hline
\end{tabular}

The IAPE results for forecasting relative returns are an improvement on those for total returns, suggesting better performance of the IAPE when forecasting relative returns. In short, the results of the analysis conducted demonstrate that the price-earnings ratio and the IAPE metric have the power to explain total equity returns over the period 1980-2006, but that the explanatory power of these factors is substantially more effective in explaining relative returns. Moreover, in the case of relative return forecasting, the IAPE metric dominates the price-earnings ratio over all periods surveyed with the exception of one-month forecasts. In addition, the predictive strength of the IAPE metric increases with the forecast period, with the metric being most effective over a one-year forecast period. 


\section{8}

\section{The value of the forecasting knowledge}

Having established that the IAPE metric has power in predicting future returns, the analysis in this final section turns to the task of assessing the value of the forecasting knowledge derived from the above results. The method used in this section follows Bleiberg (1989) by recalculating the IAPE quintiles for the period 1980-1995, and then using a simple asset allocation model to guide portfolio choices between equities and bonds for the period 1996-2006. Following Bleiberg (1989), if the IAPE metric is in the middle quintile, an equal investment is made in equities and bonds. For each higher (lower) quintile, $x$ percent of the portfolio is shifted from equities to bonds (bonds to equities) with $x$ taking the values 0 percent, 5 percent, 10 percent, 15 percent, 20 percent and 25 percent. The 0 percent rule represents a buy-andhold portfolio that is equally weighted between equities and bonds, whilst the 25 percent rule approximates a pure switching strategy, in which an IAPE metric in the highest (lowest) quintile would result in a portfolio comprised of bonds (equities) only. Given that the analysis conducted above finds that the greatest predictive power resides in the IAPE metric applied to a one-year forecast period, the constructed portfolio's asset allocation is built using the metric to forecast twelve-month returns using annual rebalancing.
The results of the exercise are summarised in Table 8. From a return perspective, the portfolios constructed using the IAPE rule dominate the buy-and-hold strategy. Over the sample period, the buy-and-hold strategy generated an annual average return of 13.95 percent. In contrast, the returns generated using the IAPE rule range from 14.14 percent in the case of the least aggressive tactical rule, to 15.76 percent under the most aggressive 25-percentage point tactic. This result concurs with those of Tanner (1999), who finds that the returns generated by tactical rules based on the IAPE rule dominate returns generated by a buy-and-hold strategy.

However, returns are only one element of the active management equation, and the risk (for which volatility is assumed to be the closest proxy) associated with each level of return is an equally important element in evaluating the success of the tactic. On this score, the results reveal that the higher returns achieved by the tactical asset allocations are associated with greater volatility in returns. For instance, under each of the tactical rules, the minimum annual return is lower than the minimum return achieved under a buy-and-hold strategy. Also, the incidence of negative annual returns increases with the aggression of the IAPE rule tactical stances, ranging from 5.79 percent under the buy-and-hold approach to 19.83 percent under the most aggressive IAPE rule tactical positions.

\section{Table 8}

Asset allocation strategies based on IAPE quintiles (1996-2006) ${ }^{11}$

\begin{tabular}{|l|c|c|c|c|c|c|}
\hline & $\begin{array}{c}\mathbf{0 \%} \text { Moves } \\
\text { (Buy-and- } \\
\text { hold) }\end{array}$ & $\begin{array}{c}\mathbf{5 \%} \\
\text { moves }\end{array}$ & $\begin{array}{c}\mathbf{1 0 \%} \\
\text { moves }\end{array}$ & $\begin{array}{c}\mathbf{1 5 \%} \\
\text { moves }\end{array}$ & $\begin{array}{c}\mathbf{2 0 \%} \\
\text { moves }\end{array}$ & $\begin{array}{c}\mathbf{2 5 \%} \\
\text { moves }\end{array}$ \\
\hline Average return (\%) & 13.95 & 14.14 & 14.40 & 14.73 & 15.17 & 15.76 \\
\hline Minimum return (\%) & -18.56 & -18.66 & -18.66 & -18.66 & -21.71 & -29.53 \\
\hline Negative returns (\%) & 5.79 & 9.09 & 12.40 & 15.70 & 16.53 & 19.83 \\
\hline Standard deviation returns (\%) & 8.89 & 9.90 & 11.28 & 13.07 & 15.31 & 18.08 \\
\hline Return per unit of volatility & 1.57 & 1.43 & 1.28 & 1.13 & 0.99 & 0.87 \\
\hline
\end{tabular}


The most forceful evidence of risk, however, is provided by the fact that volatility in annual returns increases with the aggression of the tactical stance, rising from 8.89 percent under the buy-and-hold approach to reach 18.08 percent under the 25 -percent rule. In this vein, dividing annual average returns by units of volatility, the results show that, while investors would have been rewarded with higher returns by adopting more aggressive tactical asset allocation rules, the incremental returns do not compensate for the marginal increases in volatility. Specifically, under the buy-and-hold strategy, returns per unit of volatility of 1.57 dominate the returns per unit of volatility under all of the tactical asset allocation strategies, which decline uninterrupted from 1.43 under the least aggressive strategy to 0.87 under the most aggressive strategy. In short, from a riskadjusted perspective, the IAPE rule does not add value to portfolio results in comparison with a buy-and-hold strategy.

\section{9 \\ Conclusion}

The theoretical attraction of successfully timing the market by way of tactical asset allocations is substantial. However, evidence in the literature suggests that successful tactical asset allocation remains hard to achieve. For this reason, the search for tools that can aid tactical asset allocation is ongoing. Against this backdrop, this paper tests the power of two instruments that have been shown to have predictive power in other markets, namely the price-earnings ratio and the IAPE metric. The results of the study show that the price-earnings ratio has some power in forecasting equity returns, and that this power increases with the forecast period, but that the explanatory power of the price-earnings ratio is dominated by that of the IAPE metric. This result suggests that, contrary to the modelled result, price inflation impacts equity returns.

However, in considering tactical asset allocation, relative asset class returns are a more important consideration than the total returns of individual asset classes. For this reason, this paper explores the explanatory power of the price-earnings ratio and the IAPE metric with regard to relative returns. The results confirm the findings of the total return aspect of the study, namely that the predictive power of the IAPE metric dominates the price-earnings ratio. Further, while the IAPE metric has predictive power over shorter time horizons, the predictive power increases in an ordinal fashion over the forecast horizon and is greatest over one year.

Having established that the IAPE metric has power in predicting future returns, the final section of the paper assesses the value of the forecasting knowledge provided by the metric. The results show that the predictive power of the IAPE metric has the capacity to enhance the return component of an actively managed portfolio, and that marginal returns increase with the level of aggression in the tactical asset allocation decision. However, the results also show that, as the level of tactical aggression increases, proxies for risk, such as volatility, deteriorate, and that these measurements decline at a faster pace than returns improve. The risk-adjusted returns generated by the IAPE metric thus decline as the level of tactical aggression increases.

These results conform to evidence from South Africa and other countries, showing that market timing is a rare skill. While the IAPE metric has significant power in forecasting total and relative returns from equities, the tool does not enable the active portfolio manager to capture additional returns without introducing disproportionate risk to the portfolio. In passing, it must be noted that the use of the ALSI (mostly a resource-based index) as the subject of the study could have affected the IAPE results. Gold producers, for example, have very low or negative price-earnings ratios over much of the data series used in this study. This would have affected the metrics, including observed price-earnings quintiles, and may also have lowered the average South African price-earnings ratio across all quintiles. For this reason a more disaggregated approach to using the IAPE metric may offer more fruitful grounds for study. That said, while the IAPE tool offers some information advantages, the results produced in this study indicate that the search continues for valuable and reliable tools 
and variables that augment the return and risk elements of tactical asset management in the South African context.

\section{Endnotes}

1 The author would like to thank Douglas Mbululu for his research contribution in bringing the paper to completion and for the suggestions he made for improving the final product. The author would also like to thank Evan Gilbert, Warwick Lucas and Zane Spindler for helpful comments and editorial suggestions on earlier drafts of this paper. The author also would like to thank the two anonymous reviewers for comments and suggestions that have contributed to this paper. The usual caveats apply.

2 The terms tactical asset allocation and market timing describe the same phenomenon, and for this reason are used interchangeably in the literature and in practice. For the sake of clarity this paper uses the term tactical asset allocation throughout.

3 The observations in this regard pertain to the market as a whole, as opposed to individual securities. Elsewhere, the relationship between the price-earnings ratio and individual security returns has been considered in detail, starting with the work of Basu (1977).

4 Specifically, November's consumer price index will be available at the end of December.

5 Following Chance and Hemler's (2001) argument that higher frequency data yield more significant results than lower frequency data, but recognising that the frequency of tactical asset allocation is constrained by expense, time and information requirements, the study employs monthly data to test the IAPE metric. See also Tezel and McManus (2001:175).

6 The information for the period 1935-1995 is drawn from Tanner (1999:60); the calculations for the period 1980-2006 are derived from data supplied by Robert Shiller (www.econ.yale.edu/ shiller/ data.htm).

7 Monthly return data for equities are sourced from Datastream.

8 Figures in parenthesis are $p$ values.

9 Monthly return data for equities are sourced from Datastream, and bond returns are sourced from the South African Reserve Bank.

10 Figures in parenthesis are $p$ values.

11 All return figures are reported on the basis of rolling one-year returns, measured as a percentage, unless otherwise specified.

\section{References}

BASU, S., 1977. Investment performance of common stocks in relation to their price-earnings ratios: A test of the efficient market hypothesis, Journal of Finance, 32(3): 663-682.

BLEIBERG, S., 1989. How little we know, Journal of Portfolio Management, 15: 26-31.

BODIE, Z., KANE, A. \& MARCUS, A.J., 2005.

Investments, ( $6^{\text {th }}$ ed). McGraw-Hill: New York. BRINSON, G.P., HOOD, L.R. \& BEEBOWER, G.L., 1986. Determinants of portfolio preference, Financial Analysts Journal, 42(4): 39-44.

BRINSON, G.P., SINGER, B.D. \& BEEBOWER, G.L., 1991. Determinants of portfolio preference II: an update, Financial Analysts Journal, 47(3): 40-48. CAMPBELL, J.Y. \& SHILLER, R.J., 1988. Stock prices, earnings and expected dividends. Journal of Finance 43: 661-676.

CHANCE, D.M. \& HEMLER, M.L., 2001. The performance of professional market timers: daily evidence from executed strategies. Journal of Financial Economics, 62(2): 377-411.

DARST, D.M., 2003. The art of asset allocation: asset allocation principles and investment strategies for any market, McGraw-Hill: New York.

DUMONT DE CHASSART, M. \& FIRER, C., 2001. Market timing under different market conditions. Investment Analysts Journal, 54: 19-32.

FAMA, E.F., 1981. Stock returns, real activity, inflation, and money. American Economic Review, 71: 545-565. FAMA, E.F. \& SCHWERT, G.W., 1977. Asset returns and inflation. Journal of Financial Economics, 5: 115146.

FELDSTEIN, M., 1980. Inflation and the stock market. American Economic Review, 70: 839-847. FERSON, W. \& SCHADT, R., 1996. Measuring fund strategy and performance in changing economic conditions. Journal of Finance, 51: 425-462.

FIRER, C., SANDLER, M. \& WARD, M., 1992.

Market timing revisited. Investment Analysts Journal, Vol. 35 .

FIRER, C., WARD, M. \& TEEUWISSE, F., 1987.

Market timing and the JSE. Investment Analysts

Journal, Vol. 30.

FISHER, I., 1930. The theory of interest, Macmillan: New York.

GOOD, W.R., 1991. When are price/earnings ratios too high - or too low? Financial Analysis Journal 47, July/August: 9-25.

GRAHAM, B. \& DODD, D.L., 1951. Security analysis. ( $3^{\text {rd }}$ ed). McGraw-Hill: New York.

GRAHAM, B., 1959. The intelligent investor ( $\left.2^{\text {nd }} \mathrm{ed}\right)$. Revised. Harper \& Brothers: New York. 
IBBOTSON, R.G. \& KAPLAN, P.D., 2000. Does asset allocation policy explain 40, 90, or 100 percent of performance? Financial Analysts Journal, January/ February: 26-33.

JAFFE, J.F. \& MANDELKER, G., 1976. The fisher effect for risky assets: an empirical investigation. Journal of Finance, 31: 447-458.

KEYNES, J.M., 1936. The general theory of employment interest and money, Harcourt, Brace and Company: New York.

RITTER J.R. \& WARR, R.S., 2002. The decline of inflation and the bull market of 1982-1999. Journal of Financial and Quantitative Analysis, 37(1): 29-61.
SHARPE, S.A., 2002. Reexamining stock valuation and inflation: the implications of analysts' earnings forecasts. The Review of Economics and Statistics, 84(4): 632-648.

SHILLING, A.G., 1992. Market timing: better than a buy-and-hold strategy. Financial Analysts Journal, 48: 46-50.

STATMAN, M., 2000. The $93.6 \%$ question of financial advisors. Journal of Investing, Spring: 16-20.

TANNER, G., 1999. Tactical asset allocation: follow the rule of 20. Journal of Financial and Strategic Decisions, 12(2): 59-65. 